\title{
Higiene del cordón umbilical con alcohol comparado con secado natural y baño antes de su caída, en recién nacidos de término: ensayo clínico controlado aleatorizado

\author{
Alcohol versus bath and natural drying for term newborns' \\ umbilical cord care: a prospective randomized clinical trial
}

\author{
Dra. María del Carmen Covas ${ }^{a}$, Dr. Ernesto Alda ${ }^{a}$, Dra. María Sol Medina ${ }^{a}$, \\ Dra. Silvia Ventura ${ }^{a}$ Enf. Ornella Pezutti ${ }^{b}$, Lic. Ana Paris de Baezac, \\ Bioq. Josefina Silleroc y Dra. María Eugenia Esandid
}

\section{RESUMEN}

El cuidado e higiene del cordón umbilical (CU) es motivo de preocupación para los padres. Objetivos. Principal: comparar la efectividad del secado natural del CU, con la práctica habitual (alcohol), en la reducción del tiempo de caída del CU y la incidencia de infecciones en el recién nacido(RN). Secundarios: comparar la colonización bacteriana intrahospitalaria del CU, y el grado de satisfacción de los padres en ambos grupos. Población. RN de término asistidos en elServicio de Neonatología del Hospital Privado del Sur, cuyos padres consintieron participar.

Material y métodos. Estudio clínico prospectivo, controlado, abierto, aleatorizado, en dos grupos: Grupo Estudio (secado natural y baño diario con jabón neutro) y Grupo Control (alcohol $70 \%$ ). Variables principales: tiempo de caída del CU; presencia de infecciones en piel o conjuntivas en el primer mes de vida; colonización del cordón y satisfacción parental. Análisis por intención de tratamiento.

Resultados. Se analizaron 362 RN, 181 en cada grupo. La higiene con baño se asoció con una mayor frecuencia de colonización intrahospitalaria del CU (OR 1,92 [1,22 - 3,12], p <0,01) y caída del cordón más temprana (mediana [rango intercuartílico] =6,00 [3] vs. 7,00 [4] días en el grupo control; $\mathrm{p}<0,001)$. No se observó un mayor riesgodeinfecciones. El grado de satisfacción parental fue similar y elevado en ambos grupos. Conclusiones. El secado natural y baño redujo el tiempo de caída del CU; aun cuando la frecuencia de colonización fue mayor en el grupo estudio, no se encontró un riesgo mayor de infecciones en el primer mes.

Palabras claves: recién nacido, cordón umbilical, cuidado postnatal, ensayo clínico controlado.

Academia Naciona de Medicina.

Correspondencia: Dr. Ernesto Alda: eralda@criba.edu.ar

Conflicto de intereses: Ninguno que declarar.

Recibido: 3-6-2011

Aceptado: 13-7-2011 separation. Standard practice in Argentina includes frequent cleansing of the UC with alcohol and body bath only two days after its separation. The effect of different methods of UC care on its separation time and on colonization with microorganisms has been insufficiently explored. Objectives. Main: To compare the effect on time of UC separation when using body bath with neutral soap followed by natural drying of the UC vs. standard care. Secondary: a) colonization rates during hospitalization; $b$ ) incidence of skin infection and conjunctivitis and c) parental comfort with both types of care.

Population. Normal term newborns ( $\geq 37$ weeks), born at the HPS, and whose parents provided informed consent.

Methods. Open prospective controlled clinical trial, with random allocation to two groups: study group -natural drying of the UC and body bath with neutral soap- and control group -UC hygiene with alcohol $70 \%$ at each diaper change until its separation and bath two days later-. UC separation time; UC colonization during hospital stay and skin and conjunctive infections in the first 30 days of life were monitored. Analysis was by intention-to-treat.

Results. 362 newborns were included, 181 in each group. The groups were well balanced in baseline characteristics. Being in the study group was associated with a shorter time to UC separation (median [interquartile range] $=6.00$ [3] vs. 7.00 [4] days; $p$ <0.001) and an increased frequency in nosocomial UC colonization (adjusted OR= 1.92 [1.22- 3.12], $p=0.007)$. No difference in the rate of infections was observed between both groups. Parental comfort was high and similar in both groups.

Conclusions. Compared to standard practice in Argentina, body bath with neutral soap and natural drying of the UC reduced the time to cord separation. This practice increased the colonization rate, but the risk of skin and conjunctive infections was apparently not modified by it. However, the study has insufficient power for secondary outcomes. Health care providers should continue to develop evidence to support \begin{abstract}
or eliminate historical practices.
ABSTRACT

Background. Umbilical cord (UC) care is a cause of concern for parents right from birth until its

Key words: infant, newborn, umbilical cord, postnatal care, controlled clinical trial.
\end{abstract}

\section{INTRODUCCIÓN}

El cuidado del cordón umbilical, aun después de su caída, es motivo de preocupación para los padres. En 
numerosos países se promueve aún el uso de antisépticos en el cuidado del CU, argumentando el mayor riesgo de complicaciones infecciosas (onfalitis) o eventos adversos con secado natural. ${ }^{1-4}$ Sin embargo, evidencias de alta calidad, muestran que su empleo reduce el tiempo de caída del cordón, sin incrementar el riesgo de infecciones. ${ }^{5-7}$ La mayoría de estos estudios fueron realizados en países industrializados, con prácticas altamente normatizadas. ${ }^{8}$

En nuestro país, las guías de práctica clínica recomiendan el uso de alcohol en cada cambio del pañal del RN. ${ }^{9}$ La limpieza del cordón con alcohol, así como la realización del baño del RN luego de dos días de caído el CU, se repiten como prácticas históricas; sin embargo, se desconocen sus efectos sobre la incidencia de infecciones bacterianas en la piel y el muñón umbilical, y en el tiempo de su caída. Habitualmente el alcohol se emplea y comercializa al $96 \%$, cuando lo apropiado es al $70 \%$, graduación que produce efecto antiséptico por su acción sobre las proteínas de la pared bacteriana. ${ }^{10}$

Esta investigación se propuso comparar la efectividad de métodos alternativos actualmente disponibles para la higiene del CU, en el contexto de países de bajo y mediano ingreso. La hipótesis fue que el secado natural y el baño diario, lograrían acortar el tiempo de caída del cordón, sin incrementar el riesgo de infecciones en el $\mathrm{RN}$, asociándose a mayor satisfacción de los padres.

\section{OBJETIVOS}

Principal: Comparar la efectividad del secado natural y baño diario con jabón neutro en la higiene del cordón, con el uso de alcohol y baño luego de dos días de caído, para reducir su tiempo de permanencia.

Secundarios: a. Comparar la incidencia de infecciones en ombligo, piel y mucosas. b. Comparar la colonización del CU durante su internación. c. Evaluar el grado de satisfacción de los padres.

\section{POBLACIÓN Y MÉTODOS}

Diseño: Estudio clínico prospectivo, controlado, aleatorizado, abierto.

Población elegible: RN de término ( $\leq 37$ semanas de gestación) asistidos en el Servicio de Neonatología del HPS, desde el 10 de abril al 30 de setiembre de 2008. El neonatólogo actuante solicitó consentimiento informado a sus padres. Criterios de inclusión: RN cuyos padres consintieron participar en la investigación. Criterios de exclusión: RN con antecedentes de: patolo- gía perinatal que requirió control infectológico o antibióticos; madres con ruptura prematura de membranas > 12 horas; madres con lesiones en piel compatibles con infección por Staphylococcus al momento del parto; RN derivados de otras maternidades. Criterios de eliminación: ingreso a terapia intensiva neonatal luego del alta o imposibilidad de establecer contacto con los padres para el seguimiento.

\section{Selección y tamaño de la muestra}

Los RN elegibles fueron tratados en sala de partos de acuerdo a las recomendaciones vigentes en el Servicio: baño con clorhexidina al $2 \%$ e higiene del cordón con clorhexidina al 4\%. Los RN incluidos fueron asignados a uno de los grupos: Estudio (secado natural y baño diario con jabón neutro) y Control (higiene del CU con alcohol $70 \%$ en cada cambio de pañal y baño posterior a su caída). La aleatorización se realizó mediante una tabla de números al azar y se consignó el grupo en sobres opacos correlativos que se abrían en Sala de Partos. Se estimó un tamaño muestral de $316 \mathrm{RN}$ (158 por grupo). Se consideró para su cálculo una diferencia de medias en el tiempo de caída del CU entre grupos de 1,1 días a favor del grupo de secado natural, y un desvío estándar de 3,9 ; error a de 0,05 y una potencia de $80 \%$ (prueba de hipótesis a una cola). Se previó una pérdida de $15 \%$, por lo que se sobreestimó el tamaño en 25 niños más por grupo.

El protocolo fue aprobado por el Comité de Ética y el de Docencia e Investigación del HPS.

\section{Intervención}

Grupo Estudio: Durante la estadía en el hospital, los RN fueron bañados en cuna acrílica entre las 24 y 48 h de vida, en la habitación y en presencia de los padres, con agua a temperatura de $36^{\circ} \mathrm{C}$ y jabón blanco (sin perfumes). El baño fue realizado por enfermeras entrenadas, quienes explicaron y enseñaron la técnica a los padres. Se buscó involucrarlos activamente en el procedimiento para garantizar el empleo de una técnica adecuada luego del alta hospitalaria. Se destacó la importancia de dejar secar el cordón fuera del pañal, sin colocar alcohol u otro antiséptico. Asimismo, se les entregó un folleto explicativo. Para garantizar la seguridad de la intervención y reducir el riesgo de hipotermia se indicó tomar la temperatura axilar antes y después del baño.

Al alta y hasta la caída del CU: el cuidado del cordón fue realizado por el padre o la madre. Se informó a los padres de la importancia de que 
el baño fuera realizado por ellos sin delegar esta tarea en terceros (abuelos, otro familiar, etc.) no entrenados, y evitando en todo momento la hipotermia.

Grupo Control: en el hospital, se realizó el cuidado del CU con la técnica habitualmente utilizada en el Servicio (limpieza con alcohol 70\% en cada cambio del pañal). Se indicó evitar el baño hasta dos días después de la caída del CU.

Para evaluar colonización bacteriana, se realizaron dos hisopados de la base y extremo distal del CU, inmediatamente después del nacimiento y antes del baño con clorhexidina, y al alta institucional (36-60 h de vida). La toma de la muestra fue recolectada con hisopo y colocada en tubos estériles rotulados, con $1 \mathrm{~cm}^{3}$ de solución fisiológica, los que fueron remitidos al Laboratorio de Microbiología del HPS para su cultivo en: a) medios cromogénicos (Cromobrit I.U. del Laboratorio Britania); b) Agar Columbia $+5 \%$ de sangre de carnero (Laboratorio Britania). Se investigaron los gérmenes habitualmente hallados en las unidades de terapia intensiva neonatal a través de pruebas bioquímicas estandarizadas. Las placas de cultivo se incubaron durante $24 \mathrm{~h}$ a $35-37^{\circ} \mathrm{C}$. Se consideró que había colonización cuando un tipo de bacteria, no presente en el hisopado realizado al momento del nacimiento, presentó cultivos positivos en el hisopado al egreso. Las bacteriólogas desconocían los grupos de pertenencia.

\section{Descripción de las variables principales}

Variables de resultado:

1. Tiempo de caída del CU: cantidad de días desde el nacimiento hasta la caída del CU.

2. Infecciones en piel o conjuntivas: Para todas los definiciones siguientes se consideró que los padres refirieran haber observado los signos o recibido las indicaciones que se detallan durante la internación o en los 30 días de producido el nacimiento:

a. Onfalitis: Caso confirmado: a) presencia de un área roja periumbilical mayor a $5 \mathrm{~mm}$ de diámetro; y b) haber recibido la indicación de realizar tratamiento específico con antibióticos o realizado estudios bacteriológicos que fueron positivos.

Caso probable: presencia de un área roja periumbilical de más de $5 \mathrm{~mm}$ de diámetro (pero no haber recibido la indicación de tratamiento antibiótico).

b.Lesiones en piel: Caso confirmado: a) presencia de pústulas; y b) haber recibido la indicación de realizar tratamiento local o específico con antibióticos.

Caso probable: presencia de pústulas , sin recibir la indicación de tratamiento.

c. Conjuntivitis: Caso confirmado: a) presencia de secreciones en uno o ambos ojos; $b$ ) estudio bacteriológico positivo de las secreciones; y c) haber recibido la indicación de realizar tratamiento específico con antibióticos.

Caso probable: presencia de secreciones con o sin la indicación de tratamiento, pero sin confirmación bacteriológica.

d.Lesiones periungueales: Caso confirmado: a) presencia de lesiones alrededor de las uñas; y b) haber recibido la indicación de realizar tratamiento específico local.

Caso probable: presencia de lesiones alrededor de los dedos sin tratamiento.

3. Colonización del cordón:

Se definió como la presencia de crecimiento bacteriano SIN signos clínicos de infección. El grado de colonización se midió a través de la cantidad de tipos de bacterias que se desarrollan durante la estadía hospitalaria.

4. Satisfacción de los padres:

Conformidad con la higiene indicada y grado de satisfacción medido con una escala "ad hoc" del 1 al 10.

Variables independientes:

Datos de la madre: edad; años de escolaridad; gestación-paridad; patología crónica no infecciosa detectada en el embarazo; infección o uso de antibióticos. Datos del RN: sexo; tiempo de ruptura de membranas; edad gestacional; peso de nacimiento; puntuación de Apgar; alimentación (todos los niños se alimentaron con leche materna desde Sala de Partos, salvo contraindicación o negativa de sus padres a dicha conducta). Datos de internación conjunta: horas de internación conjunta; horas del primer baño (desde el nacimiento). Datos al alta: se evaluó la adherencia de los padres a la intervención por cantidad de baños o limpieza de CU con alcohol; persona que realizó el baño; cantidad de cambios de pañal (en ambos grupos).

Recolección de datos postalta: entrevista personal a los padres a los 15 días y telefónica a los 30 (con cuestionario estructurado ad hoc), para determinar tiempo de caída del CU, presencia de infección y satisfacción con el procedimiento indicado.

\section{Análisis de datos}

Se aplicó el análisis por intención de trata- 
miento. Se comparó la mediana del tiempo de caída del CU entre los grupos, por medio de la prueba de comparación de medianas. Para estimar el efecto independiente se empleó el análisis estratificado.

Se comparó la frecuencia de cada tipo de infección de piel en ambos grupos por medio de la prueba de $\chi 2$ (prueba exacta de Fisher con frecuencias esperadas $<5$ ). Empleo de la regresión logística múltiple para establecer el efecto independiente de la intervención sobre esta variable.

Se describió la proporción de CU colonizados en ambos grupos por medio de la prueba de $\chi 2$ y la regresión logística múltiple para determinar su efecto independiente.

Se comparó la proporción de padres de cada grupo que refirieron estar conformes con el procedimiento indicado, por medio de la prueba de $\chi 2$ y la media de los resultados en la escala de satisfacción en ambos grupos por la prueba de Mann-Whitney.

\section{RESULTADOS}

Descripción de la población de estudio

Durante el periodo de estudio se asistieron 768 RN vivos. Se incluyeron en el estudio 384 RN (193
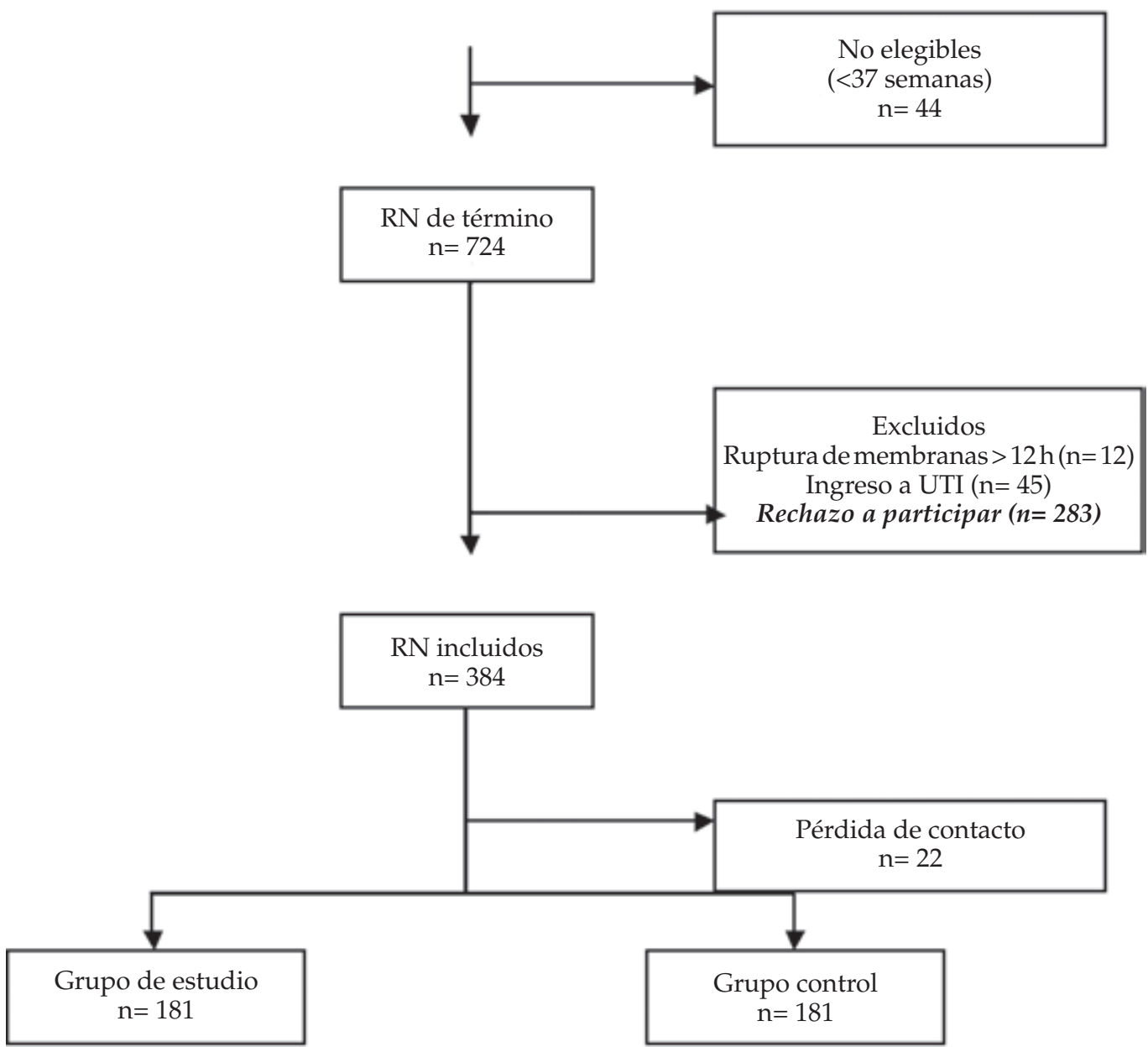

Nótese la cantidad de pacientes que no otorgaron el consentimiento informado ( $n=283): 39 \%$ de los RN de término.

UTI: Unidad de Terapia Intensiva. RN: recién nacido. 
en Grupo Estudio, y 191 en Grupo Control).Se perdieron en el seguimiento 12 y $10 \mathrm{RN}$, respectivamente; por tanto, se analizaron $181 \mathrm{RN}$ en cada grupo (Figura 1). Las características de la madre y el RN presentaron una distribución similar en ambos grupos. Sin embargo, se encontraron diferencias, estadísticamente significativas, en la forma de terminación del embarazo (Tabla 1).

Se observaron diferencias en la frecuencia de colonización según tipo de higiene. El Grupo Estudio presentó una frecuencia de colonización mayor a la observada en el Grupo Control (47\% vs. $33 \%, \mathrm{p}<0,01)$; con mayor frecuencia de colonización durante la internación por Escherichia coli $(16 \%$ vs. $11 \% ; \mathrm{p}=0,28)$ y Staphylococcus aureus $(7,2 \%$ vs. $2,2 \%$; $\mathrm{p}=0,09)$. (Figura 2$)$

Se asociaron en forma estadísticamente significativa con mayor frecuencia de colonización: parto natural, menor peso al nacer y horas en internación conjunta. (Tabla 2)

Se observaron 39 (11\%) casos confirmados y $130(36 \%)$ probables de infección en ombligo, piel y conjuntivas. No se encontraron diferencias en la frecuencia de infección en ambos grupos.

El tiempo de caída del cordón fue mayor en el Grupo Control: mediana [RI] en días= 7 [4] para el Grupo Control vs. 6 [3] días en el Grupo Estudio, $\mathrm{p}<0,001$. Otras dos variables mostraron también relación con el tiempo de caída del cordón: la colonización bacteriana del CU durante la internación (la mediana en RN con colonización fue de 6 [3] días vs. 7 [4] en aquellos sin colonización, $\mathrm{p}=0,022$ ) y el peso al nacer (índice de correlación $=0,13, p<0,01)$. Sin embargo, en este último caso el Coeficiente de correlación de Pearson entre ambas variables fue muy bajo (Tabla 3).

TABLA 1. Características de la madre y el recién nacido en los grupos de estudio y control

\begin{tabular}{|c|c|c|c|}
\hline Variables & Grupo estudio (baño) & Grupo control (alcohol) & Valor de $p$ \\
\hline \multicolumn{4}{|l|}{ Características de la madre } \\
\hline $\begin{array}{c}\text { Edad materna en años } \\
\text { Media años } \pm \mathrm{DE}\end{array}$ & $29,9 \pm 5,7$ & $30,4 \pm 5,2$ & $0,47^{*}$ \\
\hline $\begin{array}{l}\text { Años de educación formal } \\
\text { Media años educación } \pm \mathrm{DE}\end{array}$ & $13,2 \pm 3,4$ & $13,8 \pm 3,6$ & $0,07^{*}$ \\
\hline $\begin{array}{l}\text { Gestación } \\
\text { Primigesta }\end{array}$ & $40,3 \%(73 / 181)$ & $43,09 \%(78 / 181)$ & $0,56^{* *}$ \\
\hline $\begin{array}{l}\text { Antecedente de abortos } \\
\text { Mujeres con abortos previos }\end{array}$ & $11,0 \%(20 / 181)$ & $16,9 \%(30 / 177)$ & $0,10^{* *}$ \\
\hline $\begin{array}{l}\text { Patología materna crónica (PMC) } \\
\text { Mujeres con PMC }\end{array}$ & $17,1 \%(31 / 181)$ & $19,3 \%(31 / 181)$ & $0,55^{* *}$ \\
\hline $\begin{array}{l}\text { Infección materna } \\
\text { Mujeres con IM }\end{array}$ & $17,1 \%(31 / 181)$ & $19,3 \%(35 / 179)$ & $0,55^{* *}$ \\
\hline $\begin{array}{l}\text { Terminación del embarazo } \\
\text { Parto espontáneo } \\
\text { Parto instrumental } \\
\text { Cesárea con trabajo de parto } \\
\text { Cesárea sin trabajo de parto }\end{array}$ & $\begin{array}{c}43,1 \%(78 / 181) \\
0,6 \%(1 / 181) \\
17,1 \%(31 / 181) \\
39,2 \%(71 / 181)\end{array}$ & $\begin{array}{c}29,3 \%(53 / 181) \\
2,2 \%(4 / 181) \\
21,5 \%(39 / 181) \\
47,0 \%(85 / 181)\end{array}$ & $0,03^{* *}$ \\
\hline $\begin{array}{l}\text { Experiencia con higiene de cordón } \\
\text { Ninguna } \\
\text { Sí, con alcohol } \\
\text { Sí, con otro antiséptico } \\
\text { Sí, con baño }\end{array}$ & $\begin{array}{c}48,1 \%(87 / 177) \\
48,7 \%(88 / 177) \\
0,6 \%(1 / 177) \\
0,6 \%(1 / 177)\end{array}$ & $\begin{array}{c}47,7 \%(86 / 177) \\
50,3 \%(91 / 177) \\
0,0 \%(0 / 177) \\
0,0 \%(0 / 177)\end{array}$ & $0,50^{* *}$ \\
\hline Características del recién nacido & & & \\
\hline Sexo (\% de mujeres) & $48,6 \%(88 / 181)$ & $47,5 \%(86 / 181)$ & $0,83^{* *}$ \\
\hline Edad gestacional semanas (media $\pm \mathrm{DE})$ & $38,9 \pm 0,95$ & $38,8 \pm 1,04$ & $0,51^{* *}$ \\
\hline Peso al nacer $\mathrm{kg}($ media $\pm \mathrm{DE})$ & $3,33 \pm 0,36$ & $3,41 \pm 0,42$ & $0,05^{* *}$ \\
\hline Horas de internación (media $\pm \mathrm{DE}$ ) & $48,5 \pm 9,2$ & $47,5 \pm 8,2$ & $0,31^{* *}$ \\
\hline
\end{tabular}

Referencias:

(*) Se empleó la prueba de t-student para dos muestras independientes.

${ }^{* *}$ Se empleó la prueba de $\chi^{2}$; dado que más de una celda tenía un valor esperado menor a 5, se empleó la prueba exacta de Fisher. 
FIGURA 2. Frecuencia de tipos de colonización según grupos de estudio

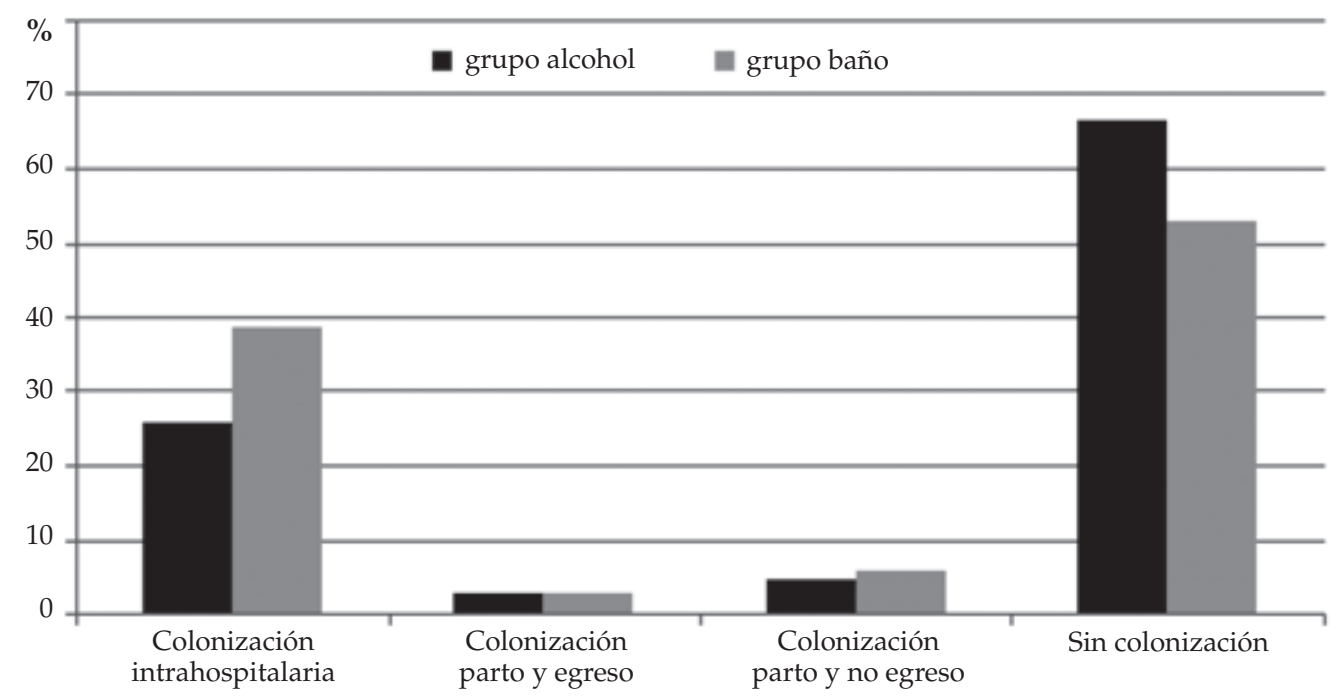

Nótese la mayor colonización intrahospitalaria (cultivo hisopado inicial negativo - prealta positivo) en el Grupo Estudio.

TABLA 2. Variables relacionadas con la colonización del cordón umbilical

\begin{tabular}{|c|c|c|c|c|}
\hline Variables & $\begin{array}{l}\text { OR }[95 \%] \\
\text { crudo }\end{array}$ & $\begin{array}{l}\text { Valor } \\
\text { de } p\end{array}$ & $\begin{array}{l}\text { OR[95\%] } \\
\text { ajustado*** }\end{array}$ & $\begin{array}{l}\text { Valor } \\
\text { de p }\end{array}$ \\
\hline \multicolumn{5}{|l|}{ Características de la madre } \\
\hline Edad materna en años & $\mathrm{NE}$ & $0,68^{*}$ & No incluido RL & No incluido RL \\
\hline Años de educación formal & NE & $0,39^{*}$ & No incluido RL & No incluido RL \\
\hline $\begin{array}{l}\text { Gestación } \\
\text { (primigesta vs. no primigesta) }\end{array}$ & $\begin{array}{c}1,15 \\
{[0,65.2,03]}\end{array}$ & $0,61^{* *}$ & No incluido RL & No incluido RL \\
\hline Antecedente de abortos & $\begin{array}{c}0,7 \\
{[0,4.1,4]}\end{array}$ & $0,33^{* *}$ & No incluido RL & No incluido RL \\
\hline Patología materna crónica & $\begin{array}{c}0,78 \\
{[0,5.1,6]}\end{array}$ & $0,78^{* *}$ & No incluido RL & No incluido RL \\
\hline Infección materna & $\begin{array}{c}1,15 \\
{[0,65-2,03]}\end{array}$ & $0,86^{* *}$ & No incluido RL & No incluido RL \\
\hline $\begin{array}{l}\text { Terminación del embarazo } \\
\text { (parto natural vs. cesárea) }\end{array}$ & $\begin{array}{c}1,45 \\
{[0,93-2,28]}\end{array}$ & $0,1^{* *}$ & $\begin{array}{c}1,9 \\
{[1,2-3,3]}\end{array}$ & 0,01 \\
\hline Sexo & $\begin{array}{c}1,5 \\
{[0,97-2,38]}\end{array}$ & $0,06^{* *}$ & $\begin{array}{c}1,6 \\
{[0,9-2,5]}\end{array}$ & 0,07 \\
\hline Edad gestacional (semanas) & NE & $0,98^{*}$ & No incluido RL & No incluido RL \\
\hline Peso al nacer $(\mathrm{kg})$ & NE & $0,02 *$ & $\begin{array}{c}2,1 \\
{[1,12-3,81]}\end{array}$ & 0,02 \\
\hline Horas de internación & NE & $0,037^{*}$ & $\begin{array}{c}1,04 \\
{[1,01-1,07]}\end{array}$ & 0,003 \\
\hline Grupo (baño vs. alcohol) & $\begin{array}{c}1,8 \\
{[1,15-2,81]}\end{array}$ & $0,009^{* *}$ & $\begin{array}{c}1,92 \\
{[1,22-3,12]}\end{array}$ & 0,007 \\
\hline
\end{tabular}

Referencias:

$\mathrm{RL}=$ regresión logística; $\mathrm{NE}=$ no se estima por tratarse de una variable numérica continua.

${ }^{*}$ ) estimado por medio de la prueba de $\chi 2$;

${ }^{* *}$ ) estimado por medio de la prueba de Mann- Whitney;

$\left({ }^{* *}\right)$ estimado por medio de la regresión logística múltiple. 
Se realizó un análisis estratificado para determinar el efecto independiente del tipo de higiene y colonización del CU, en el tiempo de caída del cordón, siendo mayor en el grupo que fue higienizado con alcohol tanto en el grupo que presentó colonización intrahospitalaria, como en aquel que no la presentó. La asociación entre tiempo de caída de cordón y colonización bacteriana desapareció al estratificar el análisis por el tipo de higiene (Tabla 4). Por tanto, el tipo de higiene de cordón posee un efecto independiente en el tiempo de caída.

En ambos grupos, más del $90 \%$ de los padres refirieron estar conformes con el tipo de cuidados indicados. Sin embargo, se observaron diferencias en la proporción de madres que modificaron el tipo de higiene indicada (9\% en el Grupo Estudio vs. $1 \%$ en el Control, $p<0,001)$.

\section{DISCUSIÓN}

Este estudio compara la efectividad de distintas alternativas para el cuidado del CU; el secado natural, si bien se asocia con una mayor frecuencia de colonización durante la internación, no incrementa el riesgo de onfalitis ni infecciones en piel, faneras y conjuntivas, comparado con el uso de alcohol al 70\%; reduce el tiempo de caída del cordón y no muestra diferencias en el grado de satisfacción de los padres.

TABLA 3. Variables relacionadas con el tiempo de caída del cordón

\begin{tabular}{|c|c|c|}
\hline Variables independientes numéricas & Coeficiente correlación & Valor de $\mathrm{p}^{*}$ \\
\hline Edad de la madre & $-0,06$ & 0,18 \\
\hline Años de educación & $-0,13$ & 0,80 \\
\hline Edad gestacional & $-0,02$ & 0,67 \\
\hline Peso al nacer & 0,13 & $0,01^{*}$ \\
\hline Horas de internación & 0,07 & 0,15 \\
\hline Variables independientes categóricas & Mediana días [RI] & Valor de $\mathrm{p}^{* *}$ \\
\hline \multicolumn{3}{|l|}{ Antecedente de abortos } \\
\hline Sí & $7[5]$ & 0,17 \\
\hline No & $6[3]$ & \\
\hline \multicolumn{3}{|l|}{ Patología materna crónica } \\
\hline Sí & $7[4]$ & 0,78 \\
\hline No & $6[3]$ & \\
\hline \multicolumn{3}{|l|}{ Presencia de infección materna } \\
\hline Sí & $7[3,25]$ & 0,35 \\
\hline No & $6[3]$ & \\
\hline \multicolumn{3}{|l|}{ Experiencia higiene de cordón } \\
\hline Ninguna & $6[3]$ & 0,91 \\
\hline Con alcohol & $7[3]$ & \\
\hline \multicolumn{3}{|l|}{ Sexo del recién nacido } \\
\hline Masculino & $7[3]$ & 0,12 \\
\hline Femenino & $6[3]$ & \\
\hline \multicolumn{3}{|l|}{ Forma de terminación del embarazo } \\
\hline Parto & $6[3]$ & 0,31 \\
\hline Cesárea con trabajo de parto & $7[4]$ & \\
\hline Cesárea sin trabajo de parte & $6[3]$ & \\
\hline \multicolumn{3}{|l|}{ Grupo según higiene } \\
\hline Alcohol & $7[4]$ & $0,001^{* *}$ \\
\hline Baño & $6[2,5]$ & \\
\hline \multicolumn{3}{|l|}{ Colonización } \\
\hline Con colonización intrahospitalaria & $6[3]$ & $0,022^{* *}$ \\
\hline Sin colonización intrahospitalaria & $7[4]$ & \\
\hline
\end{tabular}

Referencias:

${ }^{*}$ ) Se estimó por medio del índice de correlación de Pearson a pesar que la relación fue estadísticamente significativa, el índice de correlación fue muy bajo.

$(* *)$ Se estimó por medio de la prueba de Mann-Whitney. 
Estos resultados coinciden con los reportados por Zupan y col..$^{5-7}$ En estas revisiones sistemáticas, se evidenció que el cuidado del cordón con antisépticos, si bien redujo su colonización, en especial por Staphylococcus aureus (RR [IC95\%] = 0,30 $[0,16,0,55])$, no disminuyó el riesgo de infección en el RN (RR [IC95\%]= 0,63 [0,19, 2,06]), prolongando su tiempo de caída (diferencia de medias [IC95\%]= 3,51 [-0,41, 7,43]). La heterogeneidad de los estudios, y el hecho de que todos fueron realizados en países con altos ingresos, son dos aspectos que se destacan en las conclusiones. Su extrapolación a países de bajos recursos no es adecuada, dado el posible déficit en la atención neonatal y el riesgo relativamente elevado de muerte por infección del CU. ${ }^{10-13}$

Esta investigación fue realizada en un servicio de neonatología no público, cuyas condiciones y práctica asistencial, a pesar de encontrarse en un país de bajos y medianos ingresos, son similares a las observadas en países desarrollados. ${ }^{14-16}$ La higiene de manos es una práctica adoptada y valorada por todo el personal. Asimismo, el RN se aloja con su madre en habitaciones individuales, donde es cuidado por enfermeras especializadas. Estas prácticas contribuirían "per se" a reducir el riesgo de infecciones neonatales de manera significativa.

Este estudio demuestra que el uso de antisépticos como el alcohol, reduce la colonización del cordón; sin embargo, las implicancias clínicas que podría tener este hallazgo en la ocurrencia de infecciones, así como en el tiempo de la caída del cordón, son de difícil interpretación. Acorde a los resultados, la colonización no incrementaría el riesgo de infecciones, al menos, en instituciones que cuentan con una atención neonatal especializada. Las revisiones 5-7 señalan que Staphylococcus aureus es la bacteria más frecuentemente identificada en la colonización de cordón; mientras que, en nuestro hospital, fue Escherichia coli. Similares resultados observamos en una presentación previa. ${ }^{17}$

Algunos autores asocian la caída del cordón más temprana con su colonización; ${ }^{18}$ la prolongación del tiempo de caída de cordón se explicaría por la desaparición de procesos necrobióticos de gérmenes contaminantes. ${ }^{19}$ Sin embargo, en nuestro estudio, esta relación desaparece, al mostrar el efecto independiente que posee el uso de antisépticos.

El temor a que el baño y secado natural se asociara con riesgo más elevado de infección neonatal, fue uno de los aspectos más discutidos durante el diseño del estudio. El estudio piloto (20 casos), no mostró complicaciones. Tres auditorias focalizadas en infección neonatal, no demostraron mayor riesgo en el Grupo Estudio, por lo que se decidió completar la cantidad de casos requeridos. Los resultados finales demostraron que la higiene con baño y secado no se asoció con un mayor riesgo de infecciones, en particular de onfalitis; la frecuencia de esta infección fue prácticamente la misma en ambos grupos, y si bien, dada su baja incidencia, este hallazgo podría atribuirse a una falta de potencia del estudio, nuestros resultados son consistentes con los de la revisión sistemática. ${ }^{20}$

La higiene con alcohol está fuertemente arraigada en la población; lo que podría explicar la

TABLA 4. Análisis estratificado para determinar el efecto independiente del tipo de higiene del cordón y colonización del CU durante la estadía en el hospital

\begin{tabular}{|c|c|c|c|c|c|}
\hline $\begin{array}{l}\text { Estrato: CON colonización } \\
\text { intrahospitalaria }\end{array}$ & $\begin{array}{l}\text { Mediana } \\
\text { días }[R I]\end{array}$ & $\begin{array}{l}\text { Valor } \\
\text { de p }\end{array}$ & $\begin{array}{l}\text { Estrato: SIN colonización } \\
\text { intrahospitalaria }\end{array}$ & $\begin{array}{l}\text { Mediana } \\
\text { días }[R I]\end{array}$ & $\begin{array}{l}\text { Valor } \\
\text { de p }\end{array}$ \\
\hline Grupo higiene con alcohol & $7[3]$ & 0,007 & Grupo higiene con alcohol & $7[4]$ & $<0,001$ \\
\hline Grupo higiene con baño & $6[3]$ & & Grupo higiene con baño & $6[3]$ & \\
\hline $\begin{array}{l}\text { Estrato: grupo } \\
\text { higiene alcohol }\end{array}$ & $\begin{array}{l}\text { Mediana } \\
\text { días }[R I]\end{array}$ & $\begin{array}{l}\text { Valor } \\
\text { de p }\end{array}$ & $\begin{array}{l}\text { Estrato: grupo } \\
\text { higiene baño }\end{array}$ & $\begin{array}{l}\text { Mediana } \\
\text { días }[R I]\end{array}$ & $\begin{array}{l}\text { Valor } \\
\text { de } p\end{array}$ \\
\hline Con colonización al egreso & $7[3]$ & 0,31 & Con colonización al egreso & $6[3]$ & 0,13 \\
\hline Sin colonización al egreso & $7[4]$ & & Sin colonización al egreso & $6[3]$ & \\
\hline
\end{tabular}

La relación entre colonización y tiempo de caída de cordón desaparece al estratificar según tipo de higiene de cordón.

El tiempo de caída del cordón fue mayor en el grupo que fue higienizado con alcohol en los dos estratos analizados (con colonización y sin colonización). 
elevada proporción de padres que rechazaron participar en la presente investigación y la mayor frecuencia de modificación del tipo de higiene indicada en el Grupo Estudio. El cuidado del CU con antisépticos sigue siendo una conducta ampliamente aceptada, aun en países industrializados. ${ }^{21}$

Como limitación, el hecho de que los padres conocieran el grupo al que habían sido asignados, podría introducir algún tipo de sesgo en la valoración de algunos resultados, en particular el relacionado con la satisfacción parental o la valoración de signos de infección informada por los padres. Sin embargo, el control post-alta realizado por el servicio y el estrecho contacto con la familia limitó la posibilidad de fallas en la detección de onfalitis.

\section{CONCLUSIÓN}

La higiene del cordón con baño y secado natural, podría ser considerada una práctica alternativa a la higiene con alcohol, en instituciones que cuentan con una asistencia neonatal especializada, un seguimiento estricto del recién nacido y padres que contribuyan y adhieran a las recomendaciones realizadas por los profesionales.

\section{Agradecimientos}

Al Personal del Servicio de Neonatología del HPS, médicos, enfermeras y administrativa, por habernos facilitado la tarea de ejecución y recolección de datos para el presente estudio.

\section{REFERENCIAS BIBLIOGRÁFICAS}

1. Kapellen T, Gebauer C, Brosteanu O, Labitzke B et al. Higher rate of cord-related adverse events in neonates with dry umbilical cord care compared to chlorhexidine powder. Neonatology 2009;96:13-18.

2. Mullany LC, Darmstadt GL, Khatry SK, Le Clerq SC, et al. Impact of umbilical cord cleansing with $4.0 \%$ chlorhexidine on time to cord separation among newborns in southern Nepal: a cluster-randomized, community-based trial. Pediatrics 2006; 118: 1864-1871.

3. Mullany L, El Arifeen S, Winch P, Shah R, et al. Impact of $4.0 \%$ chlorhexidine cleansing of the umbilical cord on mortality and omphalitis among newborns of Sylhet, Bangladesh: design of a community-based cluster randomized trial. BMC Pediatr 2009;9:67.

4. Andrich M, Golden S. Umbilical cord care: a study of bac- itracin ointment vs. triple dye. Clin Pediatr (Phila) 1984; 23:342-344.

5. Zupan J, Garner P. Topical umbilical cord care at birth. Cochrane Database Syst Rev 2000; (2): CD001057.

6. Zupan J, Garner P, Omari A. Topical umbilical cord care at birth. Cochrane Database Syst Rev 2004;(3): CD001057.

7. Zupan J, Garner P, Omari AAA. Topical umbilical cord care at birth (Review). Cochrane Library 2009;(1).

8. Janssen P, Selwood B, Dobson S, Peacock D, et al. To dye or not to dye: a randomized, clinical trial of a triple dye/alcohol regime versus dry cord care. Pediatrics 2003; 111:15-20.

9. Guías Sociedad Argentina de Pediatría. [Acceso: 13 de julio de 2011]. Disponible en:http://www.sap.org.ar/comutemas-27-cuidados_recién_nacido.php.

10. Enkin M, Keirse MJNC, Neilson J, Crowther C et al. Mother and baby. A guide to effective care in pregnancy and childbirth. $3^{\text {rd }}$ Edition. Oxford, United Kingdom: Oxford University Press; 2000:429-38.

11. Shoaeib FM,AllSA, El-Barrawy MA. Alcohol or traditional methods versus natural drying for newborn's cord care. $J$ Egypt Public Health Assoc 2005;80(1-2):169-201.

12. Nourian M, Allaii F, Heidari A. Comparison of the effect of alcohol $70 \%$ versus dry cord care on cord bacterial colonization and cord separation time among newborns. PakJ Med Sci 2009;25(1):103-7.

13. Axelsson I. A Cochrane review on the umbilical cord care and prevention of infections. Antiseptic solutions are not necessary in developed countries but life-saving in developing countries. Lakartidningen 2002;99(14):1563-1566.

14. Golombek S, Brill P, Salice A. Randomized trial of alcohol versus triple dye for umbilical cord care. Clin Pediatr 2002;41(6):419-23.

15. Vural G, Kisa S. Umbilical cord care: a pilot study comparing topical human milk, povidone-iodine, and dry care. J Obstet Gynecol Neonatal Nurs 2006; 35(1):123-8.

16. Medves J, O'Brien B. Clearing solutions and bacterial colonization in promoting healing and early separation of the umbilical cord in healthy newborn. Can J Public Health 1997;88(6):380-2.

17. Alda E, Covas M, Ventura S, Baeza A. Umbilical cord bacterial growth in healthy newborrn, with two different antiseptics. APS-SPR Annual Meeting 2000;47(4):2272.

18. Goldmann D. The bacterial flora of neonates in intensive care-monitoring and manipulation. J Hosp Infec 1988;11(1):340-351.

19. Evens K, George J, Angst D, Schweig L. Does umbilical cord care in preterm infants influence cord bacterial colonization or detachment? J Perinatol 2004;24(2): 100-4.

20. Thompson R, Rennison W. Time of separation of the umbilical cord and its relation to infection in infancy. $\mathrm{Br}$ Med J 1987;295(6596):472-73.

21. Dore S, Buchan D, Coulas S, Hamber L et al. Alcohol versus natural drying for newborn cord care. J Obstet Gynecol Neonatal Nurs 1998;27(6):621-27.

22. Mullany L, Darmstadt G, Tielsch J. Role of antimicrobial applications to the umbilical cord in neonates to prevent bacterial colonization and infection: a review of the evidence. Pediatr Infect Dis J 2003;22:996-1002. 